\title{
Energy Intensity, Efficiency, and Investments-In the Theory and Practice
}

\section{Eugene Khartukov}

Moscow State Institute, University for International Relations (MGIMO MFA), Moscow, Russia.

\begin{abstract}
How to cite this paper: Eugene Khartukov. (2021) Energy Intensity, Efficiency, and Investments-In the Theory and Practice. Journal of Electrical Power \& Energy Systems, 5(1), 81-91. DOI: $10.26855 /$ jepes.2021.08.002
\end{abstract}

Received: June 28, 2021

Accepted: July 23, 2021

Published: August 19, 2021

*Corresponding author: Eugene Khartukov, Moscow State Institute, University for International Relations (MGIMO MFA), Moscow, Russia.

Email:khartukov@gmail.com

\begin{abstract}
Current status and the future of the energy intensity and efficiency of various energy sources are considered and analyzed. Considerations of the Rosenfeld effect, the "energy cliff" and EROI are included. The energy efficiency ratio (EER), the coefficient of performance (COP) as the equivalent measure using SI units, and the 'equivalent COP' are also considered. Energy use per unit of PPT GDP (or general economic intensity of GDP) of selected countries in 2018 is shown, with GDP of the UK and Italy being (according to the Word Bank; expressed in kg of oil equivalent per US\$), nowadays, the most energy intensive. The author uses methods of comparative and systematic analyses, which are implemented for assessing the energy intensity and efficiency globally, in the USA, UK, and Germany. Also, investments in the global and German energy sectors are considered. The paper mainly concludes that the global energy intensity tends to decrease in real terms since the beginning of the 70s while energy efficiency also decreases as non-conventional fuels are more actively developed.
\end{abstract}

\section{Keywords}

Energy intensity, GDP, the USA, UK, Germany

\section{Theory}

Though the energy intensity may be any measurement of energy input to what is produced, be it GDP, national income or any product, usually and by convenience it is understood as a ratio of energy used to produce a monetary unit of GDP. This ratio is quite stable but changes (and may change considerably) if value of energy intake changes or production efficiency undertakes any changes-increase or decrease. This phenomenon has become especially pronounced after 1973 (or after the quadraption of world oil prices) when businesses and non-commercial people started to use the much more expensive energy more efficiently.

The decoupling of energy use and economic growth was called the Rosenfeld effect, though it was revealed by the US physicist initially (perhaps, because GDP data always lag) in relation to per-capita electricity consumption in California (Figure 1).

Also, energy intensity now tends to decrease in real terms as a result of a more efficient energy use - especially in industrially developed countries.

Energy use and GDP are positively correlated, although energy intensity has declined over time and is usually lower in richer countries. Numerous factors affect the energy intensity of economies, and energy efficiency is obviously one of the most important. However, the rebound effect might limit the possibilities for energy efficiency 
improvements to reduce energy intensity. Natural science suggests that energy is crucial to economic production but mainstream economic growth theory largely ignores the role of energy. Ecological economists and some economic historians argue that increasing energy supply has been a principal driver of growth. It is possible that historically energy scarcity imposed constraints on growth, but with the increased availability of modern energy sources energy's importance as a driver of growth has declined. Empirical research on whether energy causes growth or, vice versa, is inconclusive, but meta-analysis finds that the role of energy prices is central to understanding the relationship.

The ecological economics approach does not have to reduce to an energy-only model of the economy. A key concept in biophysical economics is energy return on investment (usually abbreviated as EROI), which is the ratio of useful energy produced by an energy supply system to the amount of energy invested in extracting that energy or, in other words, a ratio that shows an economic efficiency of producing various energy sources. When the EROI is large, that means that to produce energy from that source is relatively easy and cost-effective. However, when the number is small, obtaining energy from that source is difficult and expensive. For example, when the ratio is 1 , there is no return on energy invested. According to Forbes, the break-even number is 7 [2].

On the surface, the measurement of EROI seems simple. It is just the energy output divided by the energy input. (For gasoline, for example, the output would be the energy in a gallon of gasoline, and the input would be all the energy required to make the gasoline-including oil exploration, drilling and refining). Despite the simple equation for EROI, however, there is a lot of complexity under the hood. One issue is that there is a range of EROIs in the literature for each energy source. In part, this is because various researchers use different methods for calculating the number.

Thus, Figure 2 shows the quite wide range of various estimates - and this is only for the USA.

\section{"The Rosenfeld Effect"}

Though electricity use has risen sharply in the United States, California's per capita electricity use has remained relatively flat since 1973 because of the state's strict efficiency regulations. This leveling is dubbed "The Rosenfeld Effect," after physicist Arthur Rosenfeld who has championed the energy conservation movement since the '70s.

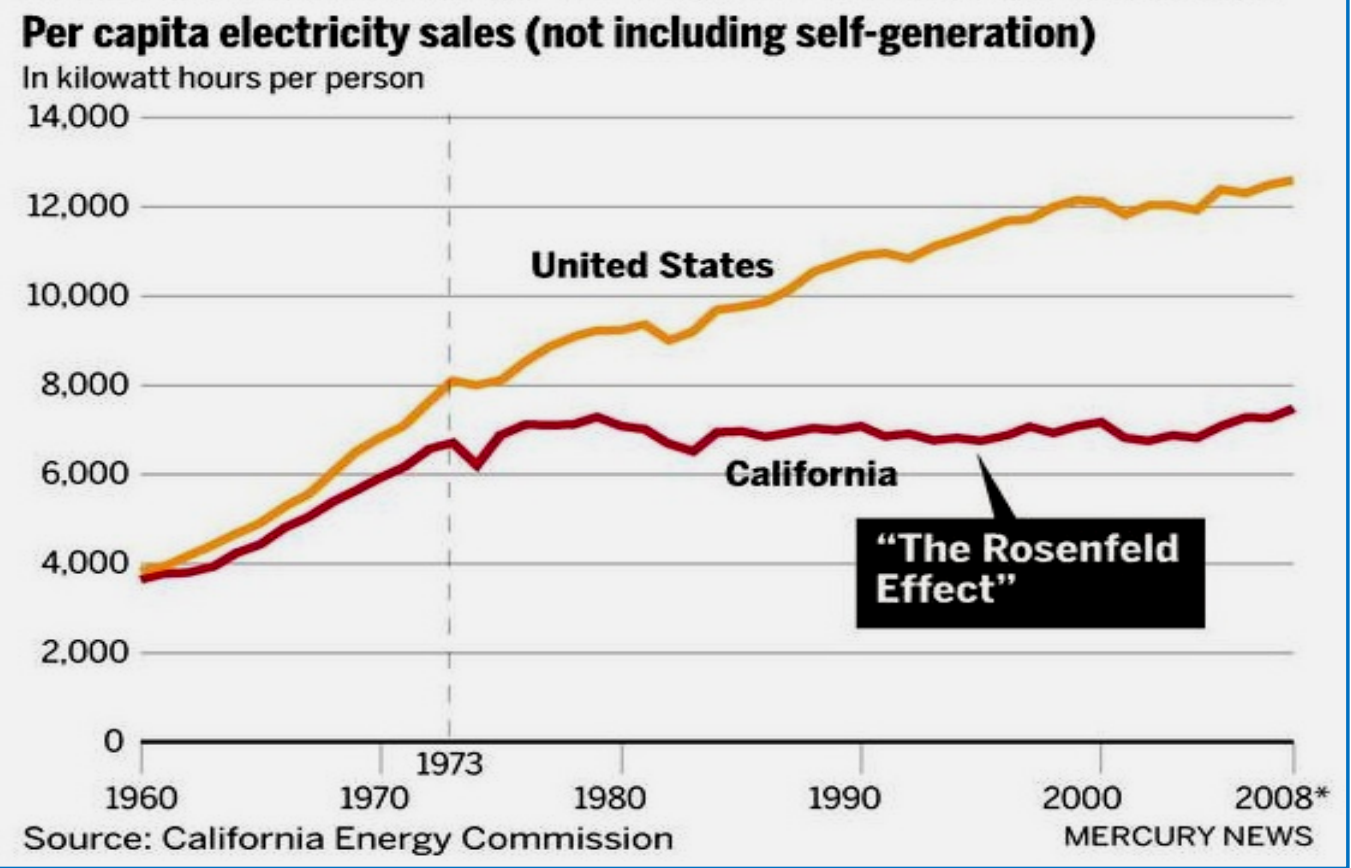

Source: http://www.wrsc.org/index.php/attach_image [1]

Figure 1. The Patterns of the Rosenfeld Effect in Californian Electricity. 


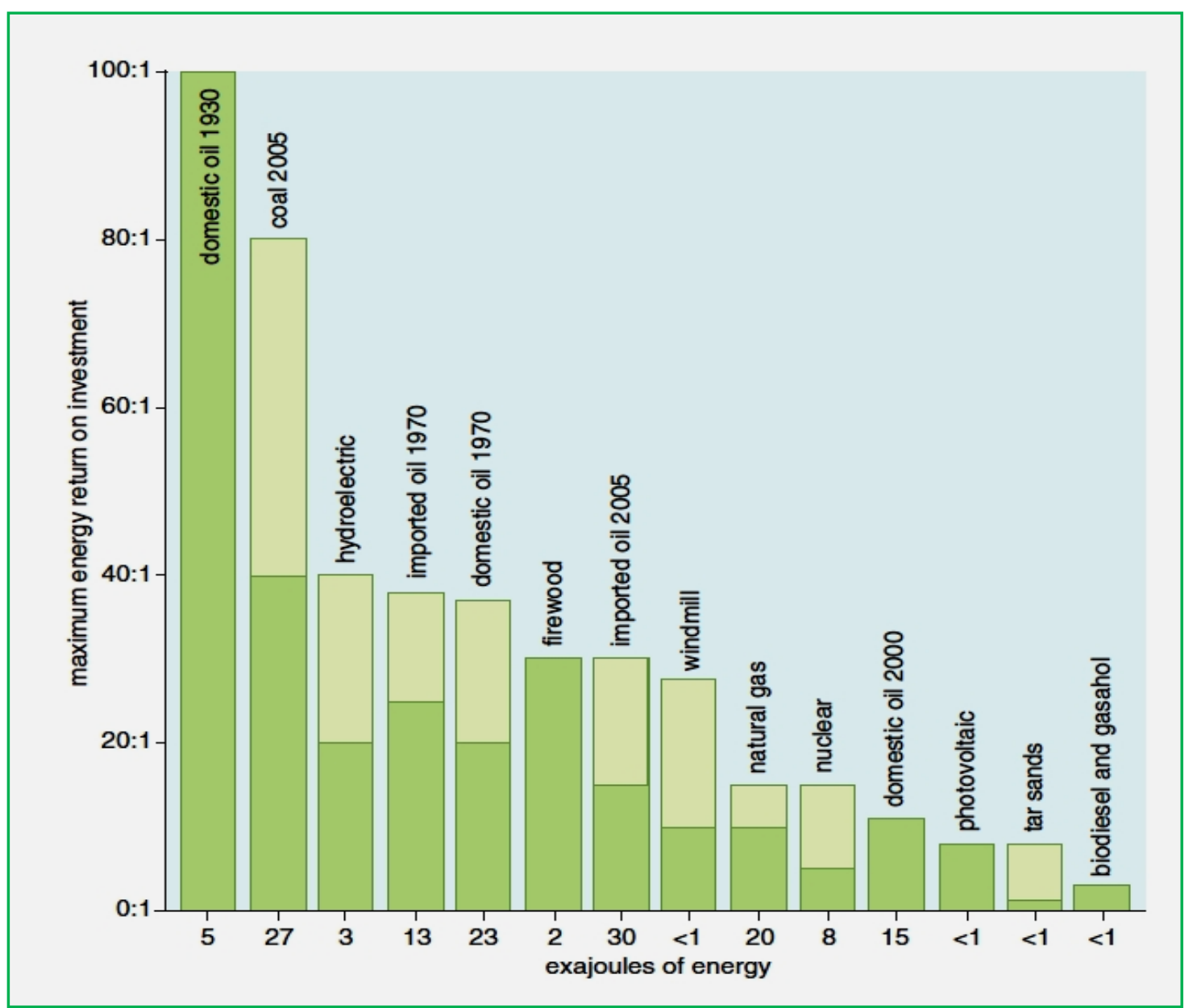

Source: Energy Return on Investment https://www.buildinggreen. com/news-article [3]

Figure 2. The Range of Estimates of Maximum EROI (as applied to the USA).

According to the World Nuclear Association, the average EROI across all energy-generating technologies in the United States is currently about 40 [3].

Globally, the ratio is lower, but still the coal mining is leading among organic fuels, with its EROI being estimated on the average at nearly 50 (Figure 3).

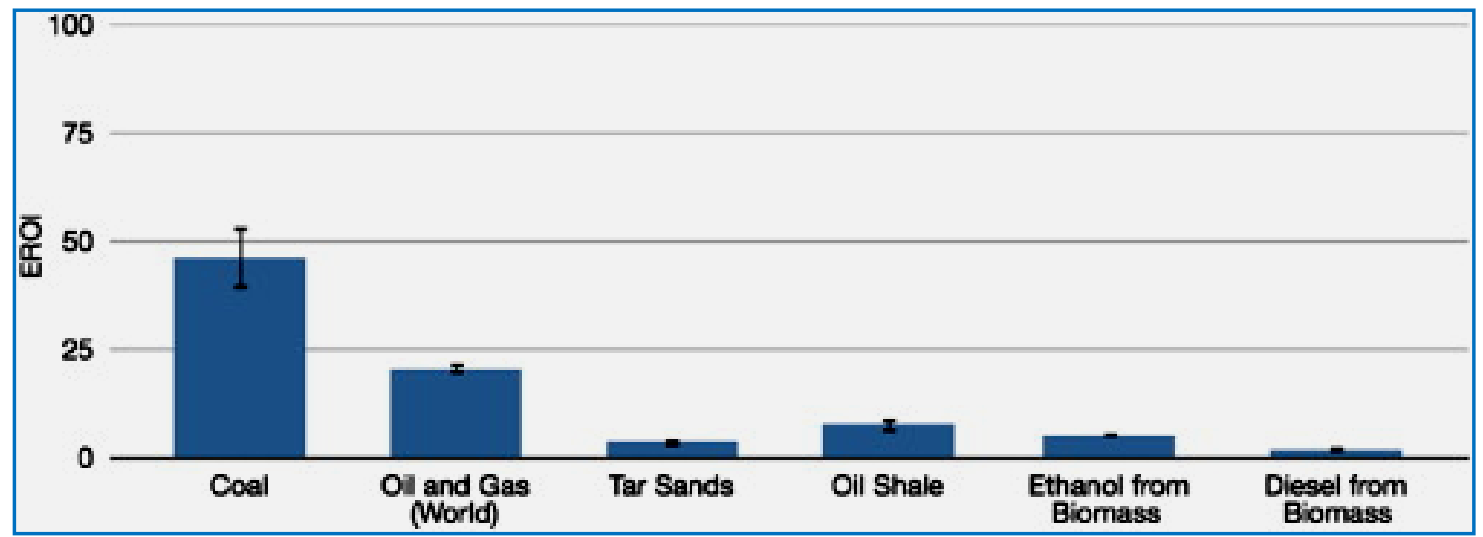

Source: http://pasini-lescienze.blogautore.espresso.repubblica.it/2020/11/05/piu-litio-e-piu-pulito-dalla-geotermia [2]

Figure 3. Average EROI in the World. 
It is noteworthy that, as new, non-conventional energy sources (like offshore and tight oil and gas, tar sands, and biofuels) are more actively involved - especially in major energy-importing nations, the EROI was declining since the mid-60s. Thus, it was estimated that only in the period of 1995-2010 the EROI of conventional oil and gas has decreased from roughly 20:1 to 12:1, a 40\% decline. The EROI of conventional combined oil-gas-tar sands has also decreased during this same period from 14:1 to $7.5: 1$, a decline of $46 \%$ [3].

The social impacts of EROI are usually illustrated with the so-called "net energy cliff". Figure 4 illustrates the possible distribution of energy employed to produce energy (light grey) and the outcome of this process, the energy available to society (dark grey) for various fuel sources ranked according to their EROI values. As EROI approaches 1:1 the ratio of the energy gained (dark grey) to the energy used (light grey) from various energy sources decreases exponentially. High EROI fuels allow a greater proportion of that fuel's energy to be delivered to society; e.g., a fuel with an EROI of 100:1 (horizontal axis) will delivers 99 percent of the useful energy (vertical axis) from that fuel to society. Conversely, lower EROI fuels deliver substantially less useful energy to society (e.g., a fuel with an EROI of 2:1 will deliver only 50 percent of the energy from that fuel to society). Therefore, large shifts in high EROI values (e.g., from 100 to 50:1) may have little or no impact on society while small variations in low EROI values (e.g., from 5 to 2.5:1) may have a far greater and potentially more "negative” impact on society.

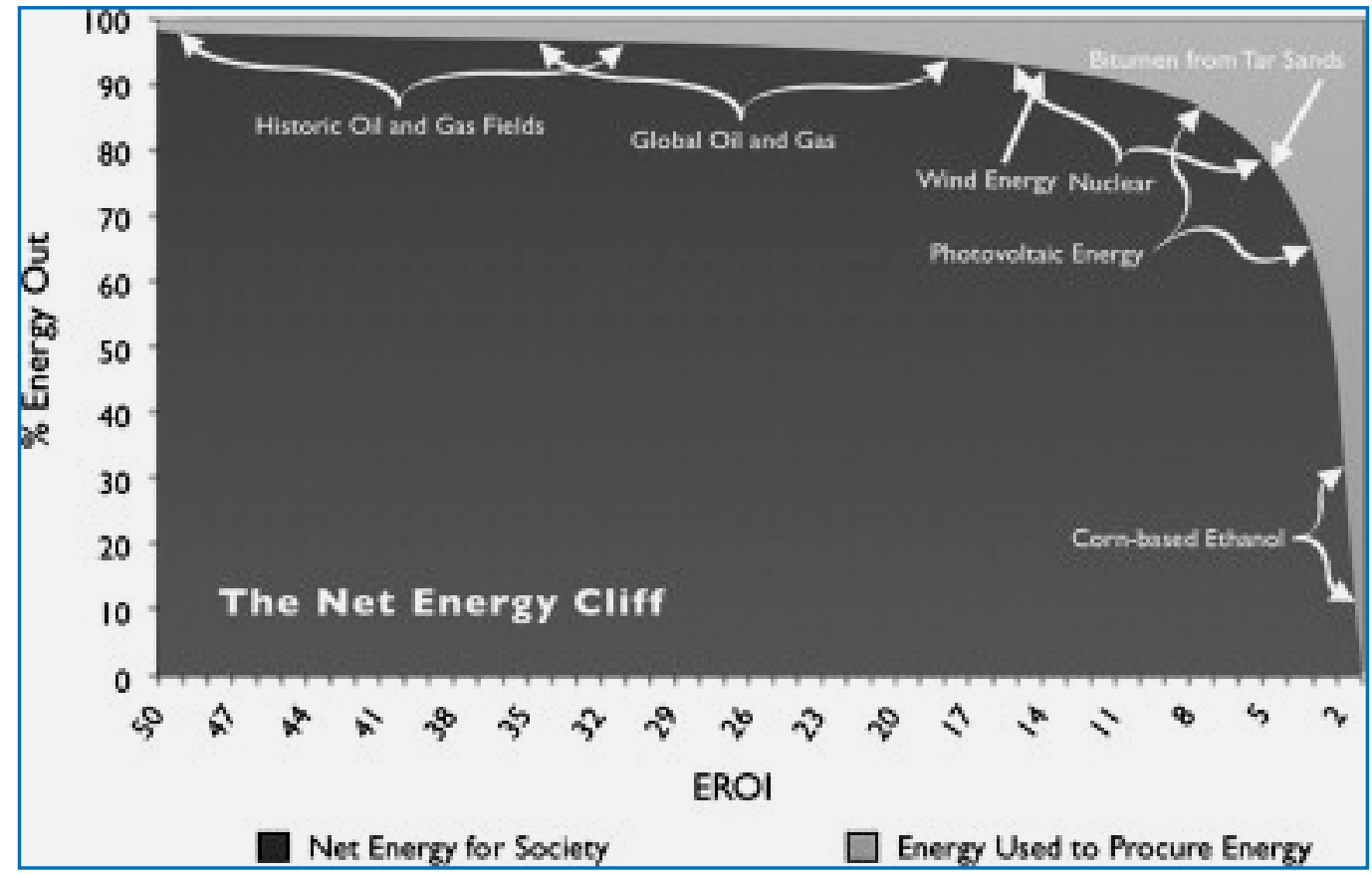

Source: https://www.sciencedirect. com/science/article/pii/S0301421513006447 [4]

Figure 4. The Net Energy Cliff.

To make the picture fuller, we have to say a couple of words about the energy efficiency ratio (EER), which is used in the USA (in engineering - for compressors and air conditioners) and is defined as the system output in Btu of heat per watt of electrical energy input. Coefficient of performance (COP) is the equivalent measure using SI units, which is widely used in the UK. A COP of 1.0 equates to an EER of 3.4.

When comparing technologies that use electrical energy with those that use heat energy, it is useful to consider the 'equivalent COP' that achieves the same carbon emission levels. In the UK, the generation of electricity emits 2.6 times as much carbon per watt when compared with burning natural gas. In terms of carbon emissions, therefore, a heat driven device with a COP of 2.5 would be equivalent to an electrically driven device with a COP of $2.5 \times 2.6$ $=6.5[5]$.

\section{Practice}

Mainly because of the differences in labour productivity energy intensity across the world surely varies but the UK and Italy are considered nowadays the most energy intensive (Figure 5). 


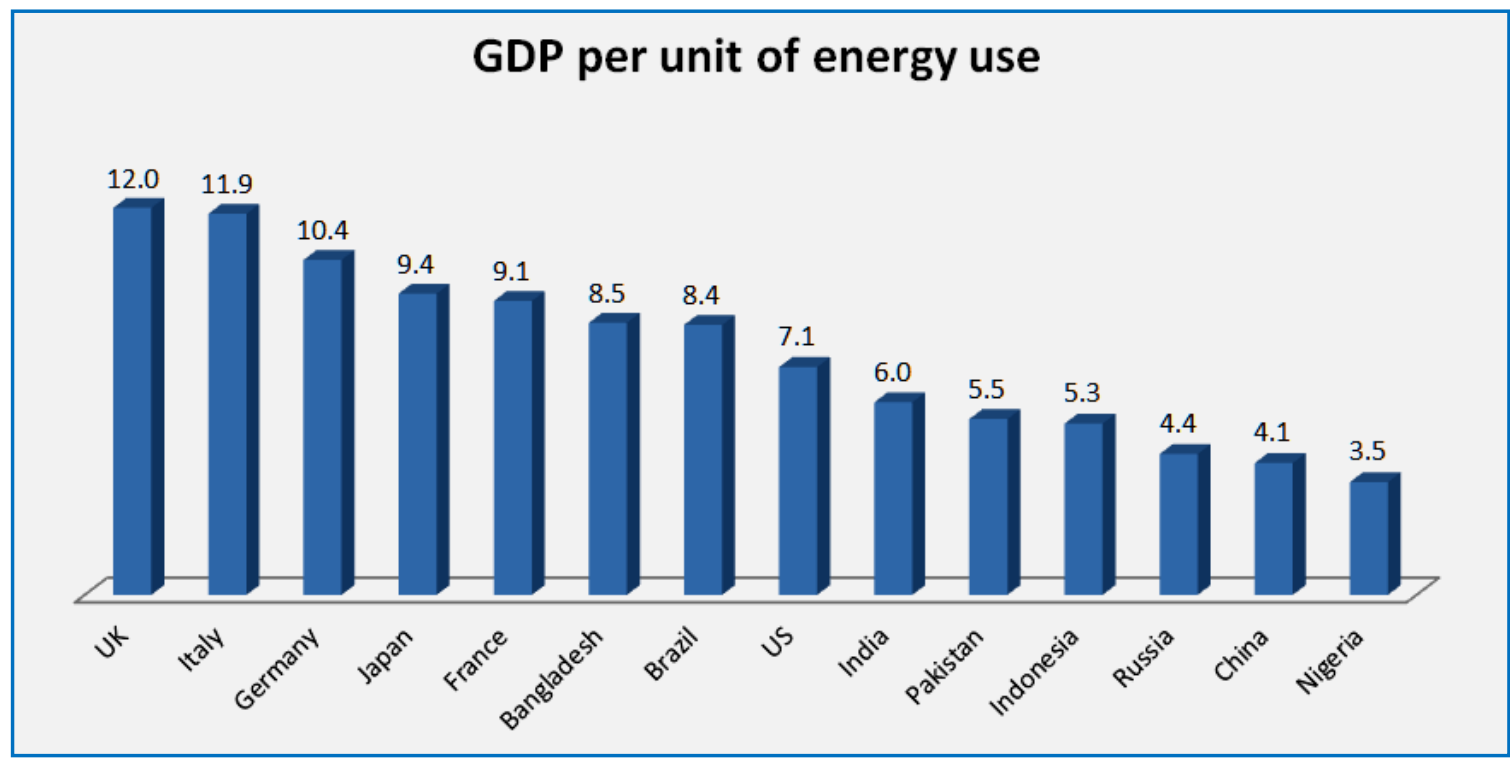

Source: https://commons.wikimedia.org/wiki/File: GDP_per_unit_of_energy_use [7]

Figure 5. Energy Intensity of GDP in Selected Countries in 2018 (according to the Word Bank; expressed in PPP), in kg of oil equivalent per US\$.

Both the world oil crises of the 70s were over and globally and in current terms energy intensity started to rise since mid-80s - but this was only in current monetary measurements - mainly due to the inflation. In real terms, say, in 2017 constant US dollars, world energy intensity diminished since 1990 by more than one-third: from almost 160 TOE/mln 2017 US\$ of GDP in 1990 down to less than 106 TOE/mln 2017 US\$ in 2020 (Figures 6 and 7).

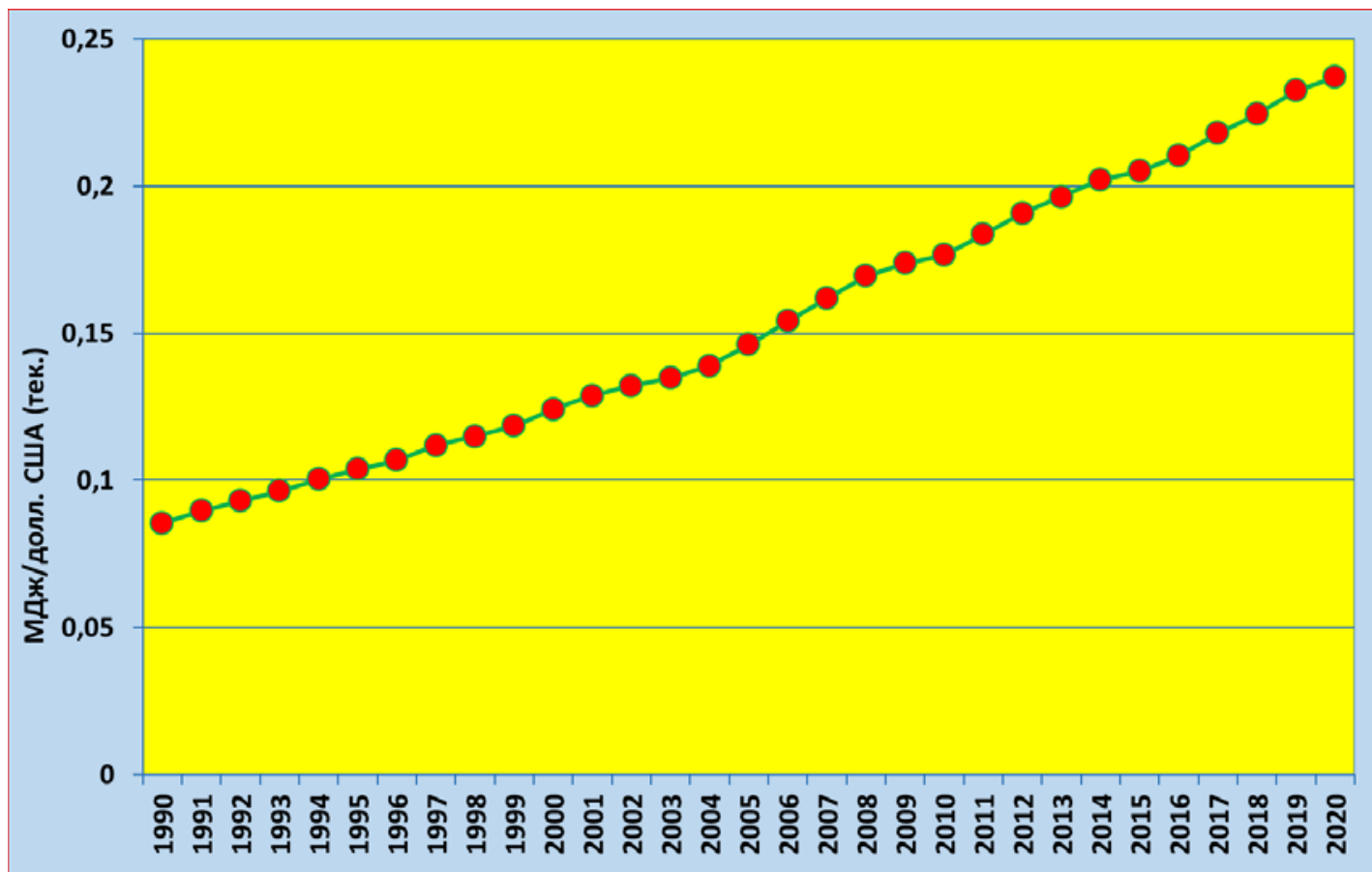

Source: compiled and drawn by the author based on https://www.bp.com/ content/dam/bp/business-sites/en/global/corporate/pdfs/energy-economics/bp-stats-review-2020-full-report] [8], https://databank.worldbank.org/reports.aspx? source=2\&series=NY.GDP.MKTP.PP.CD [9] and GAPMER/CPBS' estimates

Figure 6. Evolution of the World Energy Intensity in Current Terms in 1990-2020, in MJ per US\$ of Global GDP. 


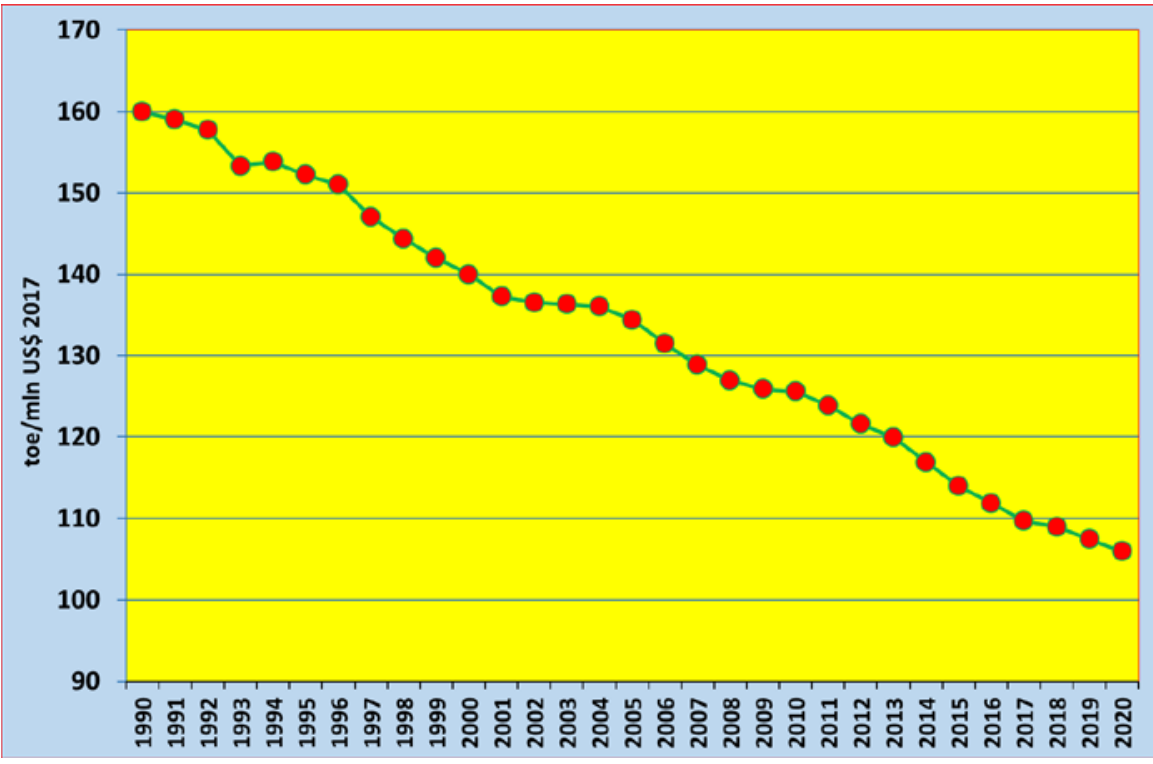

Source: compiled and drawn by the author based on https://www.bp.com/ content/dam/bp/business-sites/en/global/corporate/ pdfs/energy-economics/bp-stats-review-2020-full-report] [8], https://databank.worldbank.org/reports [9] and GAPMER/CPBS' estimates

Figure 7. Evolution of the World Energy Intensity in Real Terms in 1990-2020, in TOE per 1,000 2017 US\$ of Global GDP.

The ongoing trend toward a lower energy consumption with a relatively high economic growth (and a corresponding diminishing energy intensity) can be well seen in Germany-a major energy user (and the largest energy user in Europe). Thus, according to BP, annual primary energy in Germany decreased (as a result of more efficient use of energy, the phase-out and closure of nuclear power plants and coal mines [10-11]) since 1990 by nearly $13 \%$ : from over 15 exajoules in 1990 down to some 13 exajoules in 2019 or from $360 \mathrm{mln}$ tonnes of oil equivalent (TOE) down to less than $314 \mathrm{mln}$ TOE, whereas, per the World Bank's estimates, the country's PPP GDP rose in real terms (in constant 2017 US dollars) from less than US\$2.93 trillion in 1990 to some US $\$ 4.5$ trln in 2020. Correspondingly, real energy intensity of Ger-man GDP diminished from 122.8 tonnes of oil equivalent per 1,000 2017 US dollars down to less that 69 toe/1,000 2017 US\$ (Figure 8).

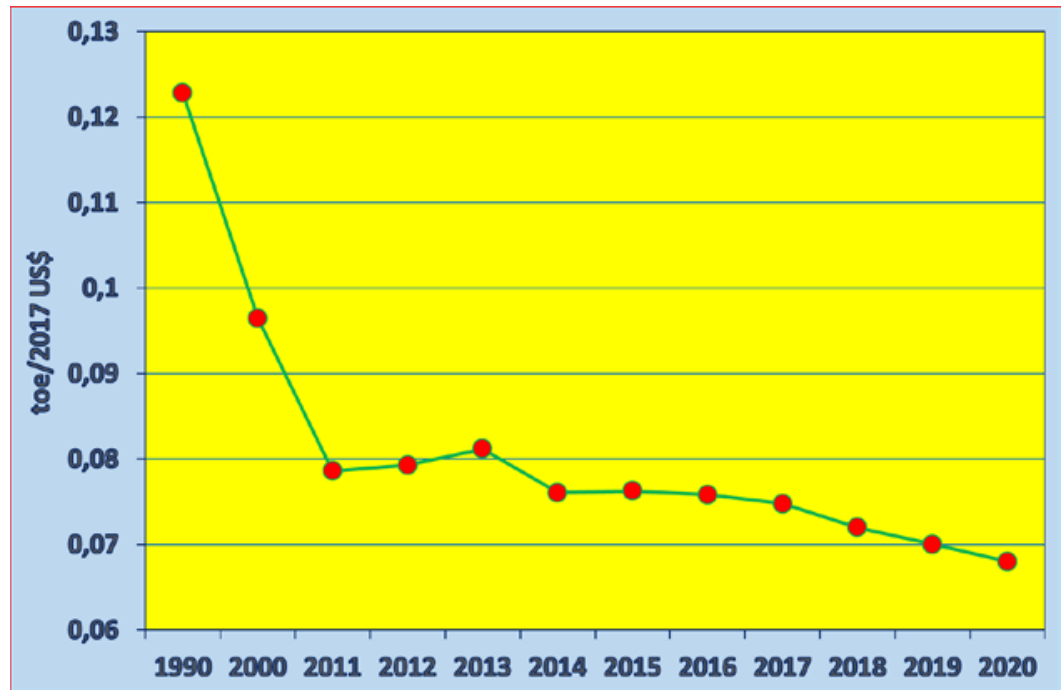

Source: compiled and drawn by the author based on https://www.bp.com/ content/dam/bp/business-sites/en/global/corporate/pdfs/energy-economics/bp-stats-review-2020-full-report] [8], https://databank.worldbank.org/reports [9] and GAPMER/CPBS' estimates

Figure 8. Energy Intensity of German PPP GDP in 1990-2020 in Real Terms (according to the World Bank), in TOE per constant 2017 US\$. 
Societies that are net energy producers may be able to supply their own energy needs through using that energy directly. An economy without sufficient domestic fuels of a type that it needs, such as oil for transport, must import these fuels and pay for them using an externally-accepted currency via some kind of surplus economic activity. This is especially the case if and as the nation develops industrially. Oil is usually the fuel of choice. The ability to purchase the oil used to maintain or grow an economy depends upon what an economy can generate to sell to the world, the oil required to grow or produce those products and their relative prices. Assume an economy that depends 100 percent on imported oil (e.g., for agriculture and transportation). Costa Rica must be a good example. It has no domestic fossil fuels (although considerable hydroelectric power), but has a fairly energy-intensive economy, and to a large degree pays for its imported oil with exported agricultural products (e.g., bananas and coffee). These are commodities highly valued in the world and hence readily sold. They are also quite energy-intensive to produce, especially when produced of the quality that sells in rich countries. Costa Rica's bananas, for example, require an amount of money equivalent to about half of their dockside purchase price to pay for the oil and petrochemicals required for their production and cosmetic quality. These production expenses consume a large portion of the economic "surplus" necessary to generate hard currency to pay for imported petroleum.

Below is presented a related graph, showing the inflation effect (Figure 9).

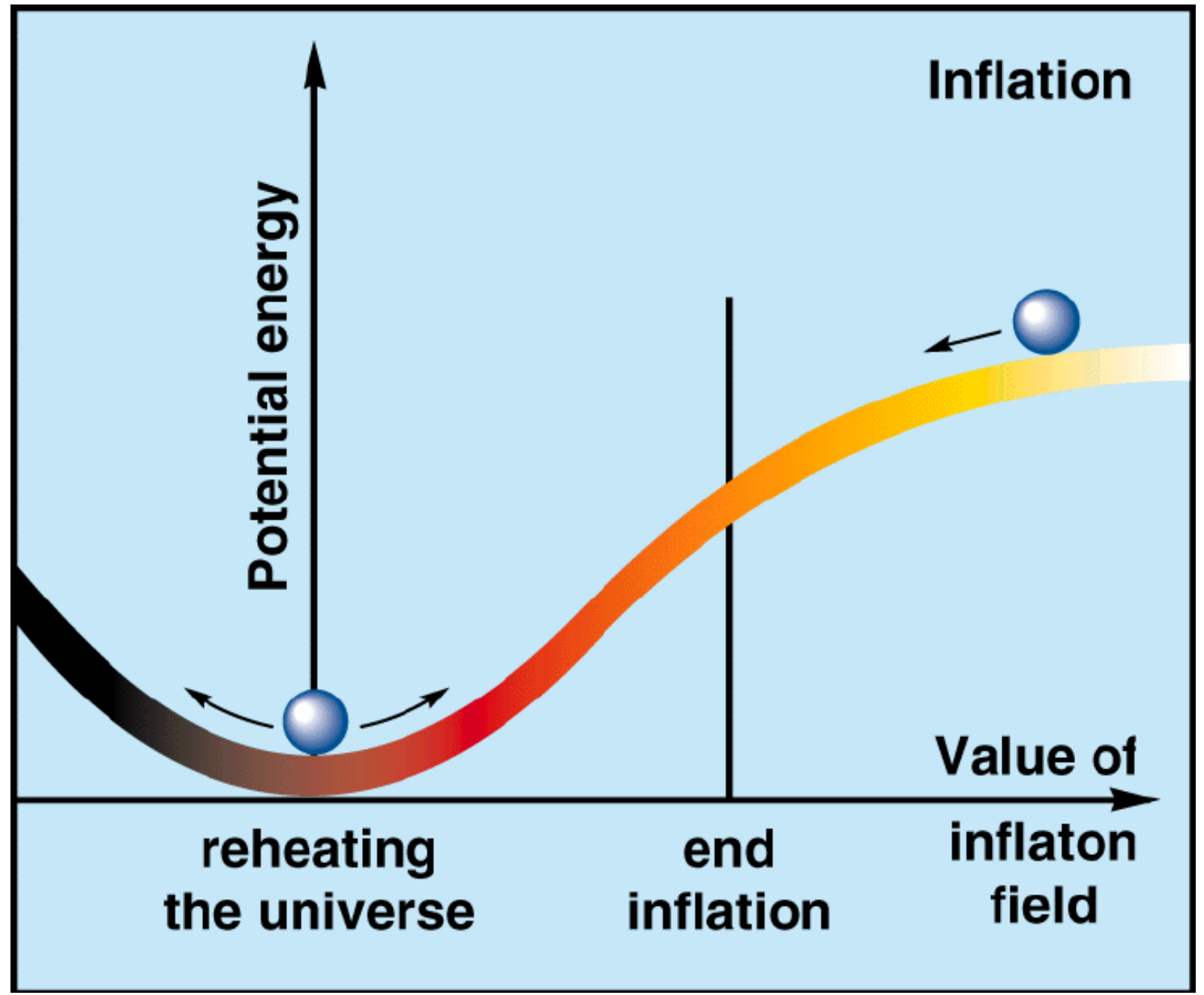

Source: https://www. researchgate.net/figure/The-inflaton-field-can-be-represented-as-a-ball-rolling-down-a-hill [12]

Figure 9. The Impact of the Inflation on Potentially Available Energy.

Globally, real energy intensity should down from 0.018 mlrd Joules/constant 2000 US\$ of GDP in 2010 to less than 0.010 mlrd Joules per the constant US\$, analysts of the New York Brooklyn College (BC) believe (Figure 10). 


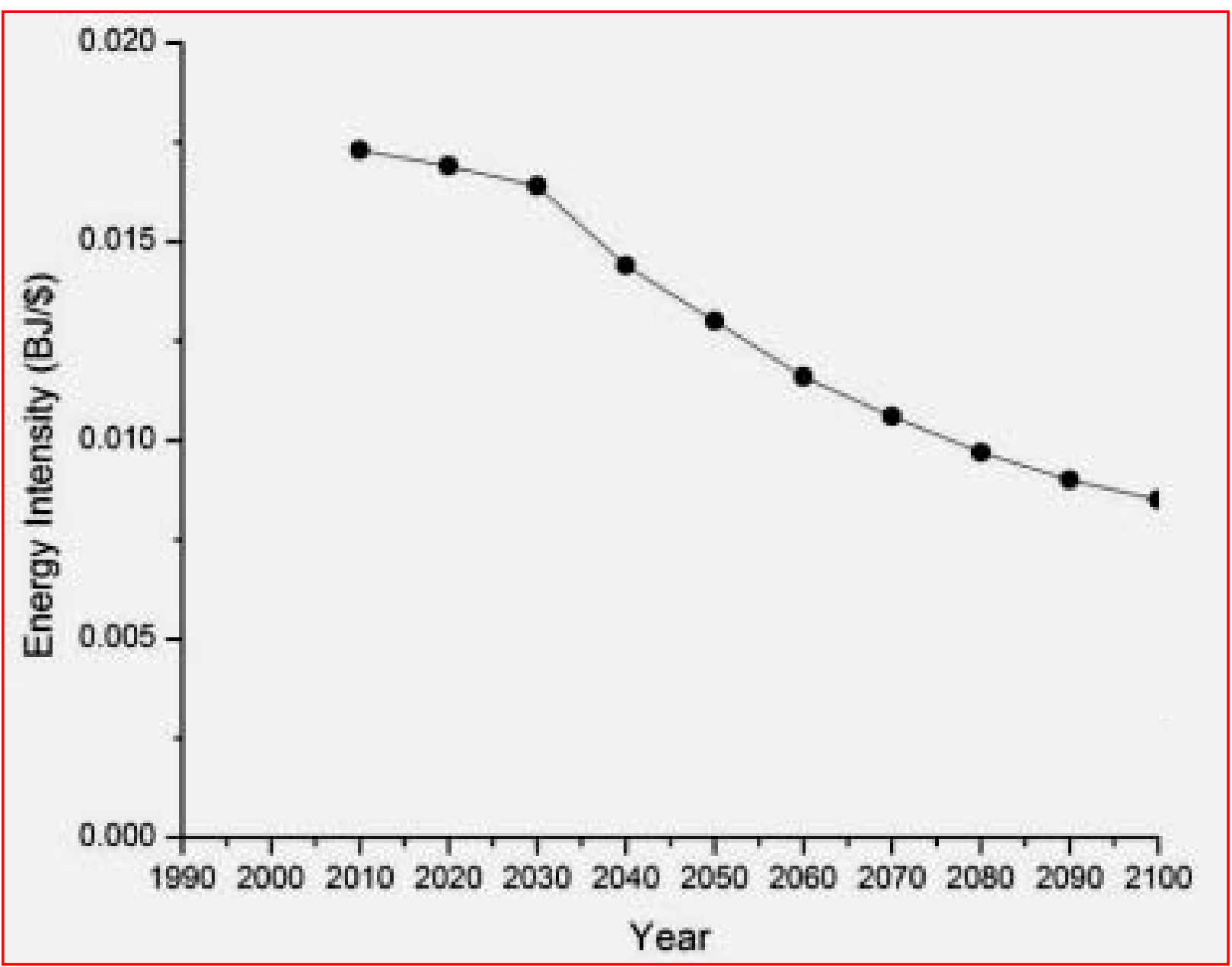

Source: https://www.researchgate.net/figure/Real-and-projected-changes-in-global-energy-intensity-units [13]

Figure 10. Global Energy Intensity in 1990-2100 (according to the New York Brooklyn College), in mlrd Joules/constant 2000 US\$ of GDP.

\section{Role and Outlooks}

Energy sectors play a very important economic role. Although global energy-related investment is projected by the International Energy Agency (IEA) to significantly drop in 2020 because of the coronavirus pandemic (by some 18\%) [14], the share of state energy investments in developing countries amounted in 2019 to 59\%, the estimated total public energy research, development and demonstration (RD\&D) budget for IEA member countries increased by $6 \%$ reaching USD 21.5 billion [15], in the USA, the FY 2020 budget request proposes $\$ 2.3$ billion in funding for energy (and this is almost 48\% of estimated federal government spending in 2020 FY [16-17].

In 2018, primary energy intensity — an important indicator of how much energy is used by the global economy-improved by just $1.2 \%$, the slowest rate since 2010 . This was significantly slower than the $1.7 \%$ improvement in 2017 and marked the third year in a row the rate has declined. It was also well below the average 3\% improvement consistent with the IEA’s Efficient World Strategy, first described in Energy Efficiency 2018.

In 2020, the IEA's WEO, published in October, focused on the next decade. In particular, the effects of the COVID-19 pandemic on the energy sector were examined in more detail.

WEO 2020 outlines four scenarios, with their respective characteristics being briefly summarised below:

COVID-19 is to be brought under control in 2021 in the "Stated Policies Scenario" (STEPS) and the world economy must reach pre-crisis levels.

In contrast, the "Delayed Recovery Scenario" (DRS) assumed that the pandemic’s impact would continue until 
2023. This would lead to this the decade showing the lowest growth rate in energy demand since the 1930s.

Thirdly, the focus in the "Sustainable Development Scenario" (SDS) is on compliance with the Paris Agreement by 2050 .

Last but not least, the new "Net Zero Emissions by 2050 case” (NZE2050) even surpasses the SDS and describes which changes are necessary in the next 10 years to reach the target of net zero emissions by 2050 .

Figure 11 shows the course of $\mathrm{CO}_{2}$-emissions from energy use and industry and different reduction levers for three scenarios until 2030.

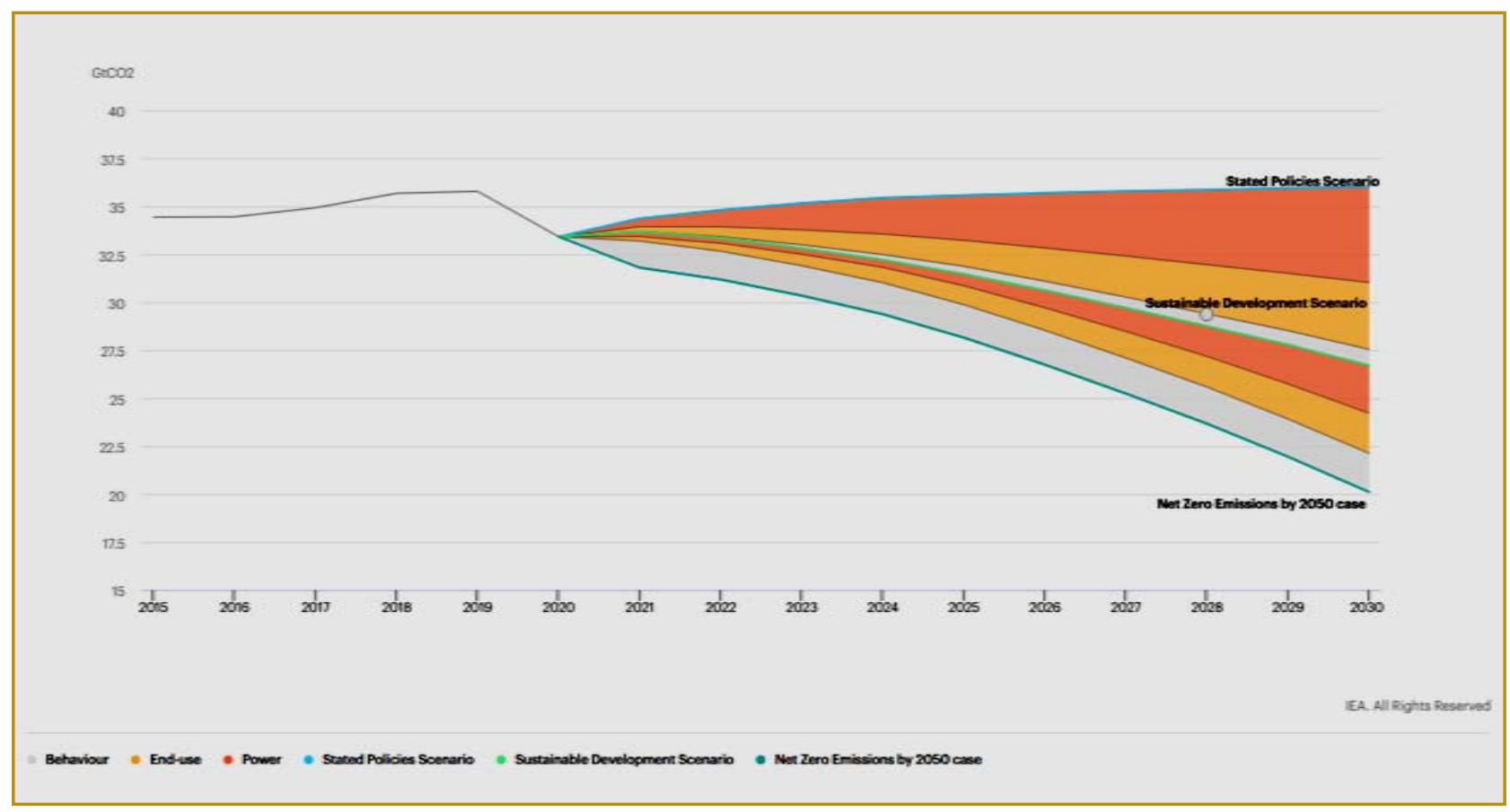

Source: File:///E:/Expansion Drive/Energy Efficiency Analysis IEA [18]

Figure 11. Energy and Industrial CO2-Emissions in WEO 2020 scenarios, in 2015-2030, in mln t of CO2 equivalent.

Interestingly, the 2020 WEO no longer contains a "Current Policies Scenario" (CPS), which normally modelled the business-as-usual case and did not assume any further efforts in climate and energy policy in addition to the existing ones as the IEA argues that the current circumstances do not allow for any business-as-usual scenario.

Still in 2020, investment in energy has suffered a sharp decline of 18-20 percent. But investment is needed, especially to advance renewable energy technologies. And it has been shown that investments in solar and wind energy are comparatively more consistent. For example, investments in offshore wind tripled in the first half of 2020 compared to the previous year. According to recent forecast of the International Energy Agency (IEA), global energy intensity improvements stepped up in the early part of this decade, but the $1.7 \%$ improvement in energy intensity of the global economy in 2017 marked the second consecutive year of slowing improvements, and analysis for 2018 shows an even slower improvement at 1.2\%. This lies well below the initial SDG (Sustainable Development Goal) target to achieve average annual energy intensity improvements of $2.6 \%$. The recent slowdown was the result of weaker energy efficiency policy implementation in many major economies, as well as strong demand growth in more energy-intensive economies. Current and planned policies, modelled in the Stated Policies Scenarios, are projected to achieve an energy intensity improvement of annual average rate of $2.4 \%$ to 2030 . This represents a doubling of the rate of progress observed in 2018, but remains below the almost $3 \%$ rate of improvement required to reach SDG.

In its Stated Policies Scenario, intensity improvements accelerate relative to recent trends in most regions, with the fastest progress observed in developing economies. In developing Asia, for example, energy intensity improves at an annual rate of 3.3\%. A number of significant energy efficiency policies, which have recently been agreed or are currently under development, are expected to boost energy intensity reduction. These include new policy packages 
announced by the European Union and China, and plans to strengthen mandatory energy performance regulations in various regions. As a result, overall global energy intensity in the Stated Policies Scenario is expected to decrease by $2.4 \%$ per year on average from 2019 to 2030 . This is a much faster rate than has been achieved in recent years, but nonetheless falls short of the $2.9 \%$ annual improvement required to meet the SDG 7.3 target for 2030 .

The Sustainable Development Scenario charts a path to meeting the objectives of SDG 7, even exceeding the energy intensity objectives of target 7.3. In this scenario, the global rate of improvement of energy intensity improvement accelerates to well over 3\% from 2019 to 2030. Much of the potential for energy intensity improvement in this scenario comes from the switch to electric vehicles for transport, improvements in efficiency across industrial sectors and stringent building energy codes for both new and existing buildings, including the electrification of building heating [19].

A recent report from the International Energy Agency (IEA) has set alarm bells ringing. Published at the end of May, the document states "The Covid-19 pandemic is having a widespread and sometimes dramatic effect on investment in the energy sector. Covid-19 is a huge blow for the energy system, but the response also provides an opportunity to orient the energy sector in a more resilient, safe and sustainable direction” [20].

Published each year, the World Energy Investment Report doesn't just provide the results for 2019. It also takes into account the first five months of 2020.

The IEA estimates that the economic recession caused by the coronavirus pandemia will likely result in an $11 \%$ drop in investment in technologies linked to renewable energy, energy efficiency and electricity storage. To maintain the commitments made to combat global warming, the IEA says that, on the contrary, this needs to double. Grids, vital for renewable energy, are also feeling the pressure, with investment down by $9 \%$.

In its latest (April 2019) analysis, "Global energy transformation: A roadmap to 2050 (2019 edition)", the international renewable-energy agency IRENA estimates that to put the world on track with the objectives of the Paris Agreement, cumulative energy investment needs to reach in the 2016-2050 period some US\$110 trillion, including US\$27 trln in renewable energy [21] (Figure 12).

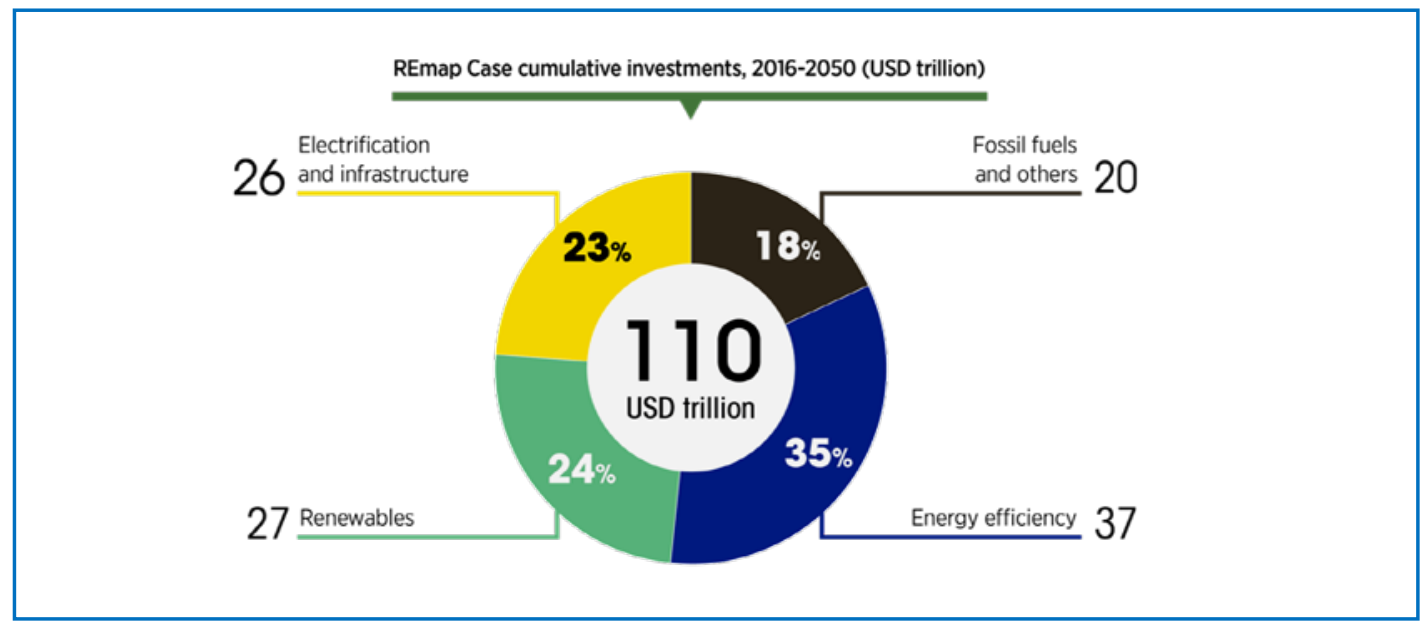

Source: https://www.irena.org/publications/2019/Apr [21]

Figure 12. Global Cumulative Energy Investments in 2016-2050, in trln US\$.

According to a recent forecast of the Spanish ecomomists Iñigo Capellán-Pérez, Carlos de Castro, and Luis Javier Miguel González of the University of Valla-dolid, the on-going transition achieving a $100 \%$ renewable electric system globally by 2060, consistent with the Green Growth narrative, could decrease the EROI of the energy system from current $\sim 12: 1$ to $\sim 3: 1$ by the mid-century, stabilizing thereafter at $\sim 5: 1$ [22].

The latest directive on energy efficiency, adopted by the European Parliament and of the EU Council on 11 December 2018, puts forward a binding EU-wide 32.5\% energy savings target for 2030, following on from the existing 20\% target by 2020 (Directive 2012/27/EU). These targets are expressed in primary and/or final energy consumption and are relative to projected levels of primary energy consumption in 2030 of 1,887 Mtoe and final energy consumption of 1,416 Mtoe. A 32.5\% reduction therefore results in 1,273 Mtoe and 956 Mtoe in 2030, respectively [23]. 


\section{References}

[1] The Rosenfeld Effect. http://www.wrsc.org/index.php/attach_image [Available in the Internet at: https://www.ise.fraunhofer. de/content/dam/ise/en/documents/News/0120_e_ISE_News_Electricity_Generation_2019] (Accessed 12 February 2021).

[2] Il Kyoto fisso. [Available in the Internet at: http://pasini-lescienze.blogautore. espresso.repubblica.it/2020/11/05/ piu-litio-epiu- pulito-dalla-geotermia] (Accessed 12 February 2021).

[3] EROI-A Tool to Predict the Best Energy Mix. [Available in the Internet at: https://www.forbes.com/ sites/jamesconca/2015/02/11] (Accessed 26 February 2021).

[4] Energy, EROI and quality of life. [Available in the Internet at: https://www.sciencedirect. com/science/article/ pii/S0301421513006447] (Accessed 26 February 2021).

[5] Ratio of Energy Returned on Energy Invested. [Available in the Internet at: https://commons.wikimedia. org/wiki/File: EROI] (Accessed 26 February 2021).

[6] Things (nearly) fall apart: The year so far in electricity, finance and computer chips. [Available in the Internet at: http://resourceinsights.blogspot] (Accessed 26 February 2021).

[7] Thermodynamic Efficiency Gains and their Role as a Key 'Engine of Economic Growth'. [Available in the Internet at: https://www.researchgate. net/ figure/primary-to-final-to-useful-energy-conversion-stages] (Accessed 26 February 2021).

[8] BP Statistical Review of World Energy 2020. [Available in the Internet at: https://www.bp.com/content/dam/ bp/business-sites/en/global/corporate/pdfs/energy-economics/bp-stats-review-2020-full-report] (Accessed 12 February 2021).

[9] World Development Indicators. [Available in the Internet at: https://data-bank. worldbank.org/reports]. (Accessed 12 February 2021).

[10] Link Between Economic Growth and Increased Energy Use Has Been Severed. [Available in the Internet at: https://www.ase. org/blog] (Accessed 2 March 2021).

[11] Net Energy Analysis: Concepts and Methods. [Available in the Internet at: https://www.sciencedirect. com/topics/engineering/ energy-ratio] (Accessed 26 February 2021).

[12] The Origin of Matter and Structure in the Universe. [Available in the Internet at: https://www.researchgate.net/figure/ The-inflaton-field-can-be-represen-ted-as-a-ball-rolling-down-a-hill] (Accessed 25 February 2021).

[13] On the Feasibility of a Timely Transition to a More Sustainable Energy Future. [Available in the Internet at: https://www. researchgate.net/figure/Real-and-projected-changes-in-global-energy-intensity-units] (Accessed 27 February 2021).

[14] World-energy-outlook. [Available in the Internet at: https://www.iea.org/re-ports] (Accessed 20 February 2021).

[15] Share-of-state-owned-energy-investments. [Available in the Internet at: https:/ /www.iea.org/data-and-statistics/charts] (Accessed 21 February 2021).

[16] U.S. Federal Budget Breakdown. [Available in the Internet at: https://www.energy.gov/articles/department-energyfy-2020-budget-request-fact-sheet] (Accessed 21 February 2021).

[17] U.S. Federal Budget Breakdown. [Available in the Internet at: https://www. the balance.com] (Accessed 21 February 2021).

[18] Energy Efficiency 2020. [Available in the Internet at: File:///E:/Expansion Drive/Energy Efficiency Analysis IEA] (Accessed 28 February 2021).

[19] Energy intensity. [Available in the Internet at: https://www.iea.org/reports/ sdg7-data-and-projections] (Accessed 15 February 2021).

[20] Energy transition facing a world crisis. [Available in the Internet at: https:/ /en.econostrum.info] (Accessed 28 February 2021).

[21] Global energy transformation. A roadmap to 2050. [Available in the Internet at: https://www.irena.org/publications/2019/Apr] (Accessed 27 February 2021).

[22] Dynamic Energy Return on Energy Investment (EROI) and material requirements in scenarios of global transition to renewable energies. [Available in the Internet at: https://www.sciencedirect.com/science/article] (Accessed 27 February 2021).

[23] Energy intensity in Europe. [Available in the Internet at: https://www.eea. europa.eu/data-and-maps/ indicators/total- primaryenergy-intensity-4] (Accessed 16 February 2021). 